Bryce Shayden (Orcid ID: 0000-0001-6425-9861)

Running head: Cognition fact sheet in youth depression

\title{
Acceptability, safety and perceived impact of providing a fact sheet to young people about cognitive symptoms in depression
}

\author{
Shayden Bryce ${ }^{1,2}$, Melanie Cooke ${ }^{1,3}$, Hok Pan Yuen ${ }^{1,2}$, Kelly Allott ${ }^{1,2 *}$ \\ ${ }^{1}$ Orygen, Parkville, Victoria, Australia \\ ${ }^{2}$ Centre for Youth Mental Health, The University of Melbourne, Parkville, Victoria, Australia \\ ${ }^{3}$ Melbourne Health, Parkville, Victoria, Australia
}

\begin{abstract}
*Corresponding author: 35 Poplar Road, Parkville, VIC, 3052, Australia; +3 99669423
kelly.allott@orygen.org.au
\end{abstract}

Word count: Abstract $=240 ;$ Body $=2999$

Key words: Youth, MDD, cognition, psychoeducation, resource

This is the author manuscript accepted for publication and has undergone full peer review but has not been through the copyediting, typesetting, pagination and proofreading process, which may lead to differences between this version and the Version of Record. Please cite this article as doi: $10.1111 /$ eip.12945

This article is protected by copyright. All rights reserved. 


\begin{abstract}
Aim: Cognitive deficits are common in young people, aged 15-25, with depression. Nevertheless, these symptoms are not routinely addressed in clinical care. This study examined the acceptability, safety, and reported impact on cognitive knowledge and strategy use, of a newly developed fact sheet (Thinking about Thinking Skills in Depression) for young people with depression.

Method: Twenty-three participants, aged 15-25 years old ( $M=19.6, S D=3.2)$, receiving community-based treatment for a depressive disorder were delivered the fact sheet by their case manager and completed pre- and post-assessments conducted three weeks apart. Primary outcomes included: acceptability; safety; subjective distress; knowledge of cognition; and use of, and confidence in using, cognitive strategies. Exploratory outcomes included depression symptoms, perceived cognitive difficulties, self-efficacy, and self-esteem. Case manager perspectives were obtained using an anonymous online survey.

Results: Participant experiences of the fact sheet were favourable. Most reported that the amount of content provided was appropriate (91\%), looked at the fact sheet again after receiving it (83\%), and tried at least one strategy (57\%). Participants reported significant improvements in their knowledge of cognitive difficulties and a greater use of, and confidence in using, cognitive strategies. Distress did not change following fact sheet delivery, supporting safety. Perceived improvements in depression symptoms and cognitive
\end{abstract}


Running head: Cognition fact sheet in youth depression

deficits, but not self-esteem or self-efficacy, were revealed. Case manager perspectives were also positive.

Conclusion: Written fact sheet resources are an acceptable, safe, and pragmatic method of delivering information about cognitive difficulties to young people with depression.

\section{Introduction}

Major depressive disorder (MDD) in young people, aged 15-25, is a leading cause of disability worldwide (World Health Organisation, 2018). Illness onset early in life can significantly disrupt educational achievement, vocational engagement, and interpersonal functioning (Gore et al., 2011; Jaeger, Berns, Uzelac, \& Davis-Conway, 2006; Lee et al., 2013). Cognitive dysfunction is recognised as a common feature of MDD in young people with rates as high as $83 \%$ (Pettit, Lewinsohn, \& Joiner, 2006). A recent meta-analysis revealed that objective cognitive impairments in domains of attention (Standardized Mean Difference $[\mathrm{SMD}]=.50)$, verbal memory $(\mathrm{SMD}=.78)$, visual memory $(\mathrm{SMD}=.65)$, and verbal reasoning and knowledge (SMD=.46) are present in young people with MDD when compared with agematched healthy controls (Goodall et al., 2018). In addition, qualitative research exploring the lived experience of young people with moderate-to-severe MDD highlights the potential for distress occurring in response to cognitive difficulties, which may contribute to lowered motivation, self-esteem, and self-efficacy (Morey-Nase et al., 2019). Evidence also indicates that cognitive impairments may persist over time, even during clinical symptom remission (Conradi, Ormel, \& de Jonge, 2011; Semkovska et al., 2019) and may significantly impact 
Running head: Cognition fact sheet in youth depression

functioning and treatment engagement (Hetrick et al., 2015; Lee et al., 2013). Cognitive difficulties are therefore an important treatment focus early in the illness course, prior to potential exacerbation of cognition-related distress or functional impairment. While clinical guidelines promote the consideration of cognitive functioning in MDD, there are limited recommendations for how best to manage these symptoms (Malhi et al., 2015).

One method of beginning to address cognitive difficulties in young people with MDD is through psychoeducation materials delivered during routine clinical care. Recent research exploring the lived experience of youth with MDD suggests that cognitive symptoms may be seldom explored in clinical practice (Morey-Nase et al., 2019). Client-centred education about cognitive symptoms represents one avenue to assist young people in better understanding and contextualising their experience, which may lessen the potential for cognition-related distress (Morey-Nase et al., 2019).

Information provision via written resources, such as booklets or leaflets, has been shown to be acceptable in many clinical and non-clinical adult groups, and beneficial when compared to controls not receiving information through increasing domain-specific knowledge or reducing anxiety. These groups have included, but are not limited to, general medicine (Johnson et al., 1986), invasive diagnostic procedures (Lai et al., 2018), mild brain injury (Ponsford et al., 2002), acute stress reactions (Scholes, Turpin, \& Mason, 2007), cancer survival (Blacklay, Eiser, \& Ellis, 1998), and parents of children awaiting outpatient surgery (Landier et al., 2018). Written educational materials have also been shown to be useful in healthy adolescents by promoting greater knowledge of safe sex (Krahé, Abraham, \& 
Running head: Cognition fact sheet in youth depression

Scheinberger-Olwig, 2005), fertility (Boivin et al., 2018), and symptoms and potential causes of depression (Schiller, Schulte-Körne, Eberle-Sejari, Maier, \& Allgaier, 2014).

In young people and adults experiencing depression, psychoeducation interventions that aim to enhance knowledge about mood-related symptoms and treatment may be associated with positive prognostic outcomes, such as greater treatment adherence, social functioning, and self-help activities, as well as reduced family burden (Bevan Jones et al., 2018; Tursi, Baes, Camacho, Tofoli, \& Juruena, 2013). Nevertheless, to our knowledge, psychoeducation resources to inform young people with MDD about cognitive symptoms and methods of selfmanagement are not readily available. This is despite the provision of accurate and timely information being considered an essential element of a stepped-care treatment approach in depression that should precede more intensive psychological and/or pharmacological intervention (Malhi et al., 2015).

The primary aims of this study were to explore whether delivering a newly developed, simple and low-tech two-page fact sheet on cognitive difficulties, Thinking about Thinking Skills in Depression, to youth with depression in routine clinical care: 1) was acceptable; 2) was safe; 3) could increase one's understanding of cognition; and 4) promote greater use of, and confidence in using, cognitive compensatory self-management strategies. It was hypothesized that participants would rate the fact sheet as acceptable and safe, and would report significantly enhanced understanding of cognition as well as greater use of, and higher confidence in using, self-management strategies after receiving the fact sheet. Changes in subjective cognition deficits, depression symptoms, self-efficacy, and self-esteem following fact sheet delivery were investigated as exploratory aims. 
Running head: Cognition fact sheet in youth depression

\section{Methods}

\subsection{Participants}

Participants were current clients of the Youth Mood Clinic (YMC) at Orygen Youth Health (OYH); a tertiary public mental health service for people aged 15-25 living in the northwestern regions of Melbourne (Rice et al., 2017). All individuals accepted into YMC were experiencing a moderate-to-severe mood disturbance, alongside moderate-to-high risk to self or others, and/or a significant functional deterioration. Participants were eligible to participate in this study if they were diagnosed with depressive disorder (i.e., MDD or Persistent Depressive Disorder; according to clinical psychiatric review), were fluent in English, and were judged to be suitable to participate by their treating case manager (i.e., no immediate risk issues; capacity to provide consent). As this was a study of acceptability and safety, cognitive impairment (subjective or objective) was not a specific inclusion criterion. Exclusion criteria included bipolar disorder, psychosis-spectrum illness, or intellectual disability.

\subsection{Procedure}

This research was approved by the Melbourne Health Human Research Ethics Committee (2018.035) and was registered prospectively with Australian and New Zealand Clinical Trial Registry on 03/04/18 (Trial ID: 12618000475246). Recruitment occurred across two YMC sites (Parkville and Sunshine) from May 2018 to March 2019. Case managers shared the contact details of potentially suitable young people with the research team. These individuals were contacted directly and provided with a verbal and written overview of the study. All participants (and parent/guardians for those aged $<18$ years) provided written consent, completed baseline assessment, and received the cognition fact sheet in their next 
Running head: Cognition fact sheet in youth depression

suitable appointment with their clinician. A follow-up assessment was scheduled within 2-4 weeks after receiving the fact sheet. Participants were reimbursed with a \$20AUS gift voucher following each assessment. Case managers were invited to provide feedback on their experience of the fact sheet using an anonymous online survey. Anonymity was maintained to encourage case managers to provide honest feedback about the new clinical resource.

\subsection{Measures}

Participant demographics (e.g., age, sex, and living situation) were collected at baseline. Estimated IQ was measured using the Word Reading subtest from the Wide Range Achievement Test-4 ${ }^{\text {th }}$ Edition (WRAT4; Wilkinson \& Robertson, 2006). Primary outcomes were: acceptability; safety; distress; and cognitive awareness, confidence, and selfmanagement. These were measured using two scales developed by the research team-the Acceptability and Safety Questionnaire (ASQ) and Cognitive Awareness and SelfManagement Questionnaire (CASMQ)-and a Subjective Units of Distress scale (SUDs).

The ASQ is a 15-item survey containing: nine Likert-style items asking the extent to which participants agree with fact sheet-related statements (e.g., "The information in the fact sheet was relevant to me" and "The information on the fact sheet worsened my mood"); four closed-ended responses (e.g., "I showed this fact sheet to another person"); and two openended short response questions (e.g., "What can you remember about the fact sheet”). The CASMQ is a 10-item questionnaire asking the extent to which participants are aware of cognitive difficulties in depression and their knowledge of, and confidence in using, cognitive self-management strategies (e.g., "I am aware of the cognitive symptoms in depression" and "I am confident in my ability to manage cognitive difficulties in everyday life”). A brief, 10-item 
Running head: Cognition fact sheet in youth depression

online questionnaire (published using Qualtrics) captured case managers’ experiences of using the fact sheet (e.g., "The fact sheet was relevant to my clients" and "The fact sheet was easy to explain and deliver"). The nine Likert-scale questions from the ASQ and all items on the CASMQ were rated on a scale from 0 (Not at all) to 100 (Very much) in 10-point intervals. CASMQ was completed at baseline and follow-up, while ASQ was completed at follow-up only. Participants rated their current distress levels from 0 (Totally relaxed) to 100 (Highest distress ever felt) using SUDs (retrieved and adapted from: at-ease.dva.gov.au), which was administered by their case manager immediately before and after receiving the fact sheet. These measures are available on request.

Exploratory measures of subjective cognitive difficulties (Perceived Deficits Questionnaire, PDQ; Sullivan, Edgley, \& Dehoux, 1990), depression symptoms (Patient Health Questionnaire, PHQ-9; Kroenke \& Spitzer, 2002), self-efficacy (General Self-Efficacy, GSE; Jerusalem \& Schwarzer, 1992), and self-esteem (Rosenberg Self-Esteem Scale, RSES; Rosenberg, 1965) were completed at baseline and follow up.

\subsection{Fact sheet development and delivery}

The two-page Thinking about Thinking Skills in Depression fact sheet was developed in consultation with young people to provide generic cognitive information (p. 1) and selfmanagement strategies (p. 2) for youth experiencing depression. Authors SB and KA (both clinical neuropsychologists) developed the initial content. Feedback from young people with lived experience of mental illness, including depression, was then obtained via an online platform meeting and a face-to-face focus group, and used to further refine the content. The written resource was designed for young people with adequate English language skills and was 
Running head: Cognition fact sheet in youth depression

relatively brief (i.e., 900 words) to support clear and simple communication of essential information. To emulate real-world clinical practice, the fact sheet was delivered to participants by their case manager. Each clinician met with a member of the research team individually to discuss the delivery standard for the fact sheet. The fact sheet can be located in supplementary material and is retrievable online from: www.orygen.org.au.

\subsection{Data analysis}

Criteria for determining acceptability and safety, as rated by participants and case managers, were established a priori. Ratings of $70 \%$ or higher were used as indication of high agreement on acceptability as well as cognitive awareness, confidence, and strategy use items from the ASQ and CASMQ. In contrast, ratings of $30 \%$ or lower were used as indication of higher safety on related items on the ASQ. Ratings of 70\% and 30\%, although arbitrary, were considered reasonable thresholds. Paired-samples $t$-tests were used to compare changes in participant subjective distress and exploratory outcomes from baseline to follow-up. Effect sizes estimates for correlated samples (Cohen's $d_{z}$ ) were calculated for each comparison (Lakens, 2013). All tests were two-tailed $(\alpha=0.05)$. Microsoft Excel and SPSS were used to analyse relevant data. When considering acceptability and safety data from case managers, only items receiving responses from $>50 \%$ of case managers were reported.

\section{Results}

\subsection{Participant characteristics}

Thirty-one individuals were approached for the study. All were eligible, but six declined to participate once given an overview of the requirements due to lack of interest. Twenty-five people provided consent; however, one participant was discharged prior to fact 
Running head: Cognition fact sheet in youth depression

sheet delivery and another could not be contacted after receiving the resource. Twenty-three people received the fact sheet and completed the follow-up assessment, with 24 providing prepost SUDs data. Participants completing all aspects of the study $(n=23)$ were, on average, 19.6 years of age ( $S D=3.2$; range: $15-25)$, identified as primarily male ( $n=15,65.2 \%)$, were born in Australia ( $n=21,91.3 \%)$, spoke English at home ( $n=22,95.7 \%)$, and were living in the family home ( $n=18,78.3 \%)$. The mean WRAT4-Word Reading Standard Score was $105.2(S D=10.1$, range: $86-124, \mathrm{n}=20$ ), consistent with estimated intellectual functioning within the Average

range. PHQ-9 scores indicated that participants were generally experiencing Moderately Severe depression symptoms at baseline $(M=16.1, S D=6.4$, range=5-27; Kroenke \& Spitzer, 2002). This sample was considered relatively typical of young people within the Orygen Youth Mood Clinic (Rice et al., 2017). Participants completed follow-up assessment approximately three weeks ( $M=20.7$ days, $S D=12.2)$ after receiving the fact sheet.

\subsection{Primary outcomes}

\subsubsection{Acceptability and safety.}

\subsubsection{Participant perspective.}

As presented in Table 1, participant opinions using the ASQ were generally favourable. Specifically, using a priori criteria, participants reported that the fact sheet was relevant, interesting and engaging, could be understood, was not upsetting, did not worsen their mood, and they would recommend it to a friend. More variable experiences were observed when participants were asked if the fact sheet was helpful or increased worry about cognitive issues in depression, with average ratings just falling outside our a priori thresholds at $67.0 \%$ and $31.3 \%$, respectively.

This article is protected by copyright. All rights reserved. 
Running head: Cognition fact sheet in youth depression

\section{[Insert Table 1]}

When provided with forced-choice questions, most participants reported that the amount of information presented was Just Right ( $n=21,91.3 \%)$. In addition, $82.6 \%(n=19)$ reported that they looked at the fact sheet again after receiving it, while $56.5 \%(n=13)$ tried one or more of the suggested cognitive strategies. In contrast, however, only just over one-third (39.1\%, $n=9)$ showed the fact sheet to another person during the follow-up period.

Twenty-four participants completed SUDs ratings before and after receiving the fact sheet. No significant difference in distress was revealed between the pre- $(M=40.1, S D=24.0)$ and post- $(M=38.3, \mathrm{SD}=26.0)$ time points, suggestive of high safety, $p=.382$.

\subsubsection{Case manager perspective.}

Nine case managers were involved in delivering the fact sheet, with several participants sharing the same primary key clinician. Seven case managers (77.8\%) provided feedback on their experience of delivering the fact sheet. These individuals were, on average, aged 32.4 years of age ( $S D=4.2$; range: 28-40) and had worked in youth mental health for 5.6 years $(S D=3.3)$, were mostly female $(n=6,85.7 \%)$, and all had psychology backgrounds. As illustrated in Table 2, when using the same a priori criteria used for young people, case managers indicated that the fact sheet was relevant to their clients, easy to use and deliver, not distressing for the clients, did not worsen the mood of their clients, and safe to administer. Further, the fact sheet increased their confidence in delivering psychoeducation about cognition and would recommend it to another clinician. Lower ratings (67.9\%) were provided when asked whether the resource increased awareness and knowledge of cognition in depression.

\section{[Insert Table 2]}


Running head: Cognition fact sheet in youth depression

\subsubsection{Cognitive awareness and self-management.}

Participants reported significant increases in their ratings on all items on the CASMQ from pre-to-post fact sheet delivery (see Table 3), with moderate-to-large effect sizes. The largest areas of self-reported change were increased knowledge of cognitive strategies, greater use of strategies to manage cognitive difficulties, and enhanced confidence in using specific strategies $\left(d_{z}=0.84-1.18\right)$.

\section{[Insert Table 3]}

\subsection{Exploratory outcomes}

As revealed in Table 4, when compared to baseline levels, participants reported moderate reductions in self-reported depression symptoms $\left(d_{z}=0.47\right)$ and perceived cognitive impairments $\left(d_{z}=0.47\right)$ following fact sheet delivery. No significant change was observed in general self-efficacy or self-esteem.

[Insert Table 4]

\section{Discussion}

Consistent with our hypotheses, the Thinking about Thinking Skills in Depression fact sheet-a simple, low-tech psychoeducational resource-is an acceptable and safe resource to deliver to young people with depression in routine clinical practice. In addition, fact sheet delivery may produce significant increases in one’s understanding of cognitive difficulties as well as greater use of, and confidence in using, compensatory self-management strategies. Exploratory investigations also revealed moderate reductions in self-reported depression symptoms and cognitive difficulties from pre-to-post fact sheet delivery among youth participants. No significant change in self-esteem or self-efficacy was observed. Together, 
Running head: Cognition fact sheet in youth depression

these findings are largely consistent with previous research suggesting that providing information using written resources (i.e., flyers, fact sheets, and leaflets) are acceptable, safe to deliver, and are helpful for increasing domain-specific knowledge and awareness among various clinical/non-clinical groups of adults (Blacklay et al., 1998; Lai et al., 2018; Landier et al., 2018; Ponsford et al., 2002; Scholes et al., 2007) and healthy adolescents (Boivin et al., 2018; Krahé et al., 2005; Schiller et al., 2014). The results also broadly support the utility of education-based interventions about clinical symptom domains in adults and young people with depression (Bevan Jones et al., 2018; Tursi et al., 2013).

The experiences of participants and case managers in this study emphasise the potential benefit of providing psychoeducational material about cognitive difficulties to young people with depression. Information delivery would appear particuarly pertinent given that this symptom domain may not be routinely addressed in tertiary public mental health (Morey-Nase et al., 2019). With consideration to the high levels of acceptability and safety endorsed by young people and case managers, delivery of basic resource materials, such as Thinking about Thinking Skills in Depression, in clinical care may represent appropriate and time-efficient platforms to discuss cognitive difficulties and support collaborative treatment planning (Simmons, Hetrick, \& Jorm, 2013). Indeed, participants in this study indicated that the fact sheet was highly relevant to them and understood the content, while clinicians indicated that the fact sheet was easy to explain and increased their confidence in delivering psychoeducation material about cognition in depression. Nevertheless, given the range of perspectives offered when young people were asked if the fact sheet was helpful (i.e., 10-100\% agreement), clinical suitability of providing cognitive resources is likely best considered on a case-by-case basis. 
Running head: Cognition fact sheet in youth depression

Delivery may be most appropriate in young people experiencing subjective or objective cognitive difficulties, particularly if these symptoms represent an important factor in a young person’s clinical formulation.

It is important to acknowledge that, while improvements in perceived cognitive difficulties and depression symptoms reported during the follow-up period are promising, the extent to which these experiences are independent from ongoing community-based treatment is unclear. Of note, fact sheet provision about cognition alone did not appear sufficient to impact self-esteem or general self-efficacy; commonly endorsed symptoms of depression that may be qualitatively related to cognitive sequela in youth (Morey-Nase et al., 2019). These symptom domains will likely require ongoing targeted psychological therapy.

\subsection{Limitations}

Since this study occurred alongside the development of a new resource in a clinical service, the Thinking about Thinking Skills in Depression fact sheet delivery was not compared to a non-fact sheet control group. This is particularly relevant when interpreting reductions in self-reported depression symptoms and cognitive deficits over the three-week follow-up period, which may have been attributable (partly or completely) to the treatment they were receiving for their depression. Young people may also have been more likely to provide commendatory ratings on targeted acceptability questions given their awareness of the study aims. Nevertheless, participants were encouraged to be honest with researchers and a range of favourable and non-favourable opinions were collected. In addition, since cognitive assessment was not completed, it was unclear whether participants were experiencing objective difficulties and whether this impacted their perspective of the fact sheet. Thus, specific recommendations 
Running head: Cognition fact sheet in youth depression

about who may benefit most, including those with measurable cognitive impairments, cannot be made. Finally, the fact sheet was delivered in a tertiary outpatient service for young people with moderate-to-severe depression. Whether these findings would generalise to other treatment settings, including primary care, is unknown.

\subsection{Conclusion}

The Thinking about Thinking Skills in Depression fact sheet is an acceptable and safe method of delivering information about cognitive difficulties and compensatory strategies in young people with depression receiving treatment in tertiary public mental health services. Fact sheet delivery may enhance cognition-specific knowledge in young people with depression and may support individualised symptom-based discussions within these services.

\section{Acknowledgements}

We wish to acknowledge the young people, their families, and OYH clinicians for their participation in this research. KA is supported by a National Health and Medical Research Council (NHMRC) Career Development Fellowship (1141207). No funding source played any role in the collection, analysis, interpretation, or publication of data.

\section{Conflict of interest}

The authors declare that there are no conflicts of interest in relation to the subject of this study.

\section{References}

This article is protected by copyright. All rights reserved. 
Running head: Cognition fact sheet in youth depression

Bevan Jones, R., Thapar, A., Stone, Z., Thapar, A., Jones, I., Smith, D., \& Simpson, S. (2018). Psychoeducational interventions in adolescent depression: A systematic review. Patient Educ Couns, 101(5), 804-816. doi:10.1016/j.pec.2017.10.015

Blacklay, A., Eiser, C., \& Ellis, A. (1998). Development and evaluation of an information booklet for adult survivors of cancer in childhood. Archives of Disease in Childhood, 78(4), 340-344. doi:10.1136/adc.78.4.340

Boivin, J., Koert, E., Harris, T., O'Shea, L., Perryman, A., Parker, K., \& Harrison, C. (2018). An experimental evaluation of the benefits and costs of providing fertility information to adolescents and emerging adults. Human Reproduction, 33(7), 1247-1253. doi:10.1093/humrep/dey107

Conradi, H. J., Ormel, J., \& de Jonge, P. (2011). Presence of individual (residual) symptoms during depressive episodes and periods of remission: a 3-year prospective study. Psychological Medicine, 41(6), 1165-1174. doi:10.1017/s0033291710001911

Goodall, J., Fisher, C. A., Hetrick, S., Phillips, L., Parrish, E. M., \& Allott, K. (2018). Neurocognitive functioning in depressed young people: A systematic review and meta-analysis. . Neuropsychology Review, 28(2), 216-231.

Gore, F. M., Bloem, P. J., Patton, G. C., Ferguson, J., Joseph, V., Coffey, C., . . Mathers, C. D. (2011). Global burden of disease in young people aged 10-24 years: a systematic analysis. Lancet, 377(9783), 2093-2102. doi:10.1016/s0140-6736(11)60512-6

Hetrick, S. E., Cox, G. R., Fisher, C. A., Bhar, S. S., Rice, S. M., Davey, C. G., \& Parker, A. G. (2015). Back to basics: could behavioural therapy be a good treatment option for

This article is protected by copyright. All rights reserved. 
Running head: Cognition fact sheet in youth depression

youth depression? A critical review. Early Intervention in Psychiatry, 9(2), 93-99. doi:10.1111/eip.12142

Jaeger, J., Berns, S., Uzelac, S., \& Davis-Conway, S. (2006). Neurocognitive deficits and disability in major depressive disorder. Psychiatry Research, 145(1), 39-48. doi:10.1016/j.psychres.2005.11.011

Jerusalem, M., \& Schwarzer, R. (1992). Self-efficacy as a resource factor in stress appraisal processes. In R. Schwarzer (Ed.), Self-efficacy: Thought control of action (pp.195213). Washington DC: Hemisphere.

Johnson, M. W., Mitch, W. E., Sherwood, J., Lopes, L., Schmidt, A., \& Hartley, H. (1986). The impact of a drug information sheet on the understanding and attitude of patients about drugs. JAMA, 256(19), 2722-2724.

Krahé, B., Abraham, C., \& Scheinberger-Olwig, R. (2005). Can safer-sex promotion leaflets change cognitive antecedents of condom use? An experimental evaluation. British Journal of Health Psychology, 10(2), 203-220. doi:10.1348/135910705X27640

Kroenke, K., \& Spitzer, R. L. (2002). The PHQ-9: A new depression diagnostic and severity measure. Psychiatric Annals, 32(9), 509-515. doi:10.3928/0048-5713-20020901-06

Lai, Y. L., Van Heuven, A., Borire, A., Kandula, T., Colebatch, J. G., Krishnan, A. V., \& Huynh, W. (2018). The provision of written information and its effect on levels of pain and anxiety during electrodiagnostic studies: A randomised controlled trial. Plos One, 13(5). doi:10.1371/journal.pone.0196917

This article is protected by copyright. All rights reserved. 
Running head: Cognition fact sheet in youth depression

Lakens, D. (2013). Calculating and reporting effect sizes to facilitate cumulative science: A practical primer for t-tests and ANOVAs. Frontiers in Psychology, 4(NOV). doi:10.3389/fpsyg.2013.00863

Landier, M., Villemagne, T., Le Touze, A., Braïk, K., Meignan, P., Cook, A. R., . . Binet, A. (2018). The position of a written document in preoperative information for pediatric surgery: A randomized controlled trial on parental anxiety, knowledge, and satisfaction. Journal of Pediatric Surgery, 53(3), 375-380.

doi:10.1016/j.jpedsurg.2017.04.009

Lee, R. S., Hermens, D. F., Redoblado-Hodge, M. A., Naismith, S. L., Porter, M. A., Kaur, M., . . . Hickie, I. B. (2013). Neuropsychological and socio-occupational functioning in young psychiatric outpatients: A longitudinal investigation. Plos One, 8(3). doi:10.1371/journal.pone.0058176

Malhi, G. S., Bassett, D., Boyce, P., Bryant, R., Fitzgerald, P. B., Fritz, K., . . Singh, A. B. (2015). Royal Australian and New Zealand College of Psychiatrists clinical practice guidelines for mood disorders. Australian And New Zealand Journal Of Psychiatry, 49(12), 1087-1206. doi:10.1177/0004867415617657

Morey-Nase, C., Phillips, L. J., Bryce, S., Hetrick, S., Wright, A. L., Caruana, E., \& Allott, K. (2019). Subjective experiences of neurocognitive functioning in young people with major depression. Bmc Psychiatry, 19(1), 209. doi:10.1186/s12888-019-2197-1

Pettit, J. W., Lewinsohn, P. M., \& Joiner, T. E., Jr. (2006). Propagation of major depressive disorder: relationship between first episode symptoms and recurrence. Psychiatry Research, 141(3), 271-278. doi:10.1016/j.psychres.2005.07.022

This article is protected by copyright. All rights reserved. 
Running head: Cognition fact sheet in youth depression

Ponsford, J., Willmott, C., Rothwell, A., Cameron, P., Kelly, A. M., Nelms, R., \& Curran, C. (2002). Impact of early intervention on outcome following mild head injury in adults. Journal of Neurology Neurosurgery and Psychiatry, 73(3), 330-332. doi:10.1136/jnnp.73.3.330

Rice, S. M., Halperin, S., Cahill, S., Cranston, I., Phelan, M., Hetrick, S. E., . . . Davey, C. G. (2017). The Youth Mood Clinic: an innovative service for the treatment of severe and complex depression. Australas Psychiatry, 25(2), 112-116.

doi:10.1177/1039856216689002

Rosenberg, M. (1965). Society and the adolescent self-image. Princeton, NJ: Princeton University Press.

Schiller, Y., Schulte-Körne, G., Eberle-Sejari, R., Maier, B., \& Allgaier, A. K. (2014). Increasing knowledge about depression in adolescents: Effects of an information booklet. Social Psychiatry and Psychiatric Epidemiology, 49(1), 51-58. doi:10.1007/s00127-013-0706-y

Scholes, C., Turpin, G., \& Mason, S. (2007). A randomised controlled trial to assess the effectiveness of providing self-help information to people with symptoms of acute stress disorder following a traumatic injury. Behaviour Research and Therapy, 45(11), 2527-2536. doi:10.1016/j.brat.2007.06.009

Semkovska, M., Quinlivan, L., O'Grady, T., Johnson, R., Collins, A., O'Connor, J., . . . Gload, T. (2019). Cognitive function following a major depressive episode: a systematic review and meta-analysis. The Lancet Psychiatry, 6(10), 851-861. doi:10.1016/S2215-0366(19)30291-3

This article is protected by copyright. All rights reserved. 
Running head: Cognition fact sheet in youth depression

Simmons, M. B., Hetrick, S. E., \& Jorm, A. F. (2013). Making decisions about treatment for young people diagnosed with depressive disorders: A qualitative study of clinicians' experiences. Bmc Psychiatry, 13. doi:10.1186/1471-244X-13-335

Sullivan, J. J. L., Edgley, K., \& Dehoux, E. (1990). A survey of multiple sclerosis. Part 1: Perceived cognitive problems and compensatory strategy use. Canadian Journal of Rehabilitation, 4, 99-105.

Tursi, M. F. D. S., Baes, C. V. W., Camacho, F. R. D. B., Tofoli, S. M. D. C., \& Juruena, M. F. (2013). Effectiveness of psychoeducation for depression: A systematic review. Australian And New Zealand Journal Of Psychiatry, 47(11), 1019-1031. doi:10.1177/0004867413491154

Wilkinson, G. S., \& Robertson, G. J. (2006). WRAT-4: Wide Range Achievement Test. Professional Manual Lutz, FL: Psychological Assessment Resources, Inc.

World Health Organisation. (2018). Depression. Retrieved from http://www.who.int/en/news$\underline{\text { room/fact-sheets/detail/depression }}$

This article is protected by copyright. All rights reserved. 
Table 1. Participant ratings of the acceptability and safety of the fact sheet

\begin{tabular}{|c|c|c|c|}
\hline \multirow[t]{2}{*}{ Item } & \multicolumn{3}{|c|}{ Response (out of 100) } \\
\hline & $M$ & $S D$ & Range \\
\hline The information in the fact sheet was relevant to me & 78.3 & 17.5 & $40-100$ \\
\hline The information in the fact sheet was interesting and engaging & 70.9 & 13.5 & $40-90$ \\
\hline The information in the fact sheet was upsetting for me & 13.0 & 20.8 & $0-60$ \\
\hline The information in the fact sheet worsened my mood & 10.9 & 19.0 & $0-70$ \\
\hline The information in the fact sheet was helpful & 67.0 & 22.5 & $10-100$ \\
\hline I could understand the information presented in the fact sheet & 93.9 & 8.9 & $70-100$ \\
\hline The information in the fact sheet made me worry about cognitive issues in depression & 31.30 & 29.3 & $0-90$ \\
\hline I wish I hadn’t received any information about cognitive issues in depression & 3.5 & 10.7 & $0-50$ \\
\hline I would recommend this fact sheet to someone else & 76.1 & 24.6 & $10-100$ \\
\hline
\end{tabular}

Note: $N=23 ; M=$ Mean; $S D=$ Standard Deviation 
Table 2. Case manager ratings of the acceptability and safety of the fact sheet

\begin{tabular}{|c|c|c|c|}
\hline \multirow[t]{2}{*}{ Item } & \multicolumn{3}{|c|}{ Response (out of 100) } \\
\hline & $M$ & SD & Range \\
\hline The fact sheet was relevant to my clients & 87.9 & 14.1 & $60-100$ \\
\hline The fact sheet was easy to explain and deliver ${ }^{\dagger}$ & 91.7 & 9.8 & $80-100$ \\
\hline On average, the fact sheet was distressing for my clients ${ }^{\dagger}$ & 11.0 & 16.0 & $0-34$ \\
\hline On average, the fact sheet worsened the mood of my clients ${ }^{\ddagger}$ & 8.3 & 8.5 & $0-20$ \\
\hline I would use this fact sheet in clinical practice & 78.6 & 22.5 & $35-100$ \\
\hline I would recommend this resource to another clinician & 87.71 & 19.0 & $51-100$ \\
\hline This is a safe intervention for young people with depression & 95.9 & 7.5 & $81-100$ \\
\hline $\begin{array}{l}\text { Using the fact sheet with my clients has increased my awareness and knowledge about } \\
\text { cognitive difficulties in depression }\end{array}$ & 67.9 & 31.2 & $29-100$ \\
\hline $\begin{array}{l}\text { Using the fact sheet with my clients has increased my confidence about delivering } \\
\text { psychoeducation about cognition }\end{array}$ & 71.6 & 27.2 & $40-100$ \\
\hline
\end{tabular}

Note: $N=7 ;{ }^{\dagger} N=6 ;{ }^{\ddagger} N=4 ; M=$ Mean; $S D=$ Standard Deviation 
Table 3. Paired samples t-tests comparing individual items of the Cognitive Awareness and Self-Management Questionnaire (CASMQ) at baseline and follow up

\begin{tabular}{|c|c|c|c|c|}
\hline \multirow[t]{2}{*}{ Item } & Baseline & Follow-up & \multirow[t]{2}{*}{ t-statistic } & \multirow[t]{2}{*}{ Effect size $\left(d_{z}\right)$} \\
\hline & \multicolumn{2}{|c|}{$\begin{array}{l}\text { Mean response out of } 100 \\
(S D)\end{array}$} & & \\
\hline I am aware of the cognitive symptoms in depression & $68.7(25.6)$ & $87.4(9.6)$ & $-3.40 * *$ & 0.71 \\
\hline I know about lifestyle factors that make cognition better or worse & $60.0(23.4)$ & $77.8(23.2)$ & $-3.23^{* *}$ & 0.67 \\
\hline I know about strategies for managing attention and concentration & $47.0(21.6)$ & $77.0(15.2)$ & $-5.27 * * *$ & 1.18 \\
\hline I am confident in my ability to manage cognitive difficulties in everyday life & $45.7(22.7)$ & $60.9(23.0)$ & $-3.03^{* *}$ & 0.63 \\
\hline $\begin{array}{l}\text { I am confident in my ability to use different strategies or techniques to help with } \\
\text { cognitive difficulties }\end{array}$ & $41.3(22.6)$ & $62.6(22.4)$ & $-4.23 * * *$ & 0.88 \\
\hline I use strategies to manage cognitive difficulties & $34.8(22.5)$ & $60.9(28.3)$ & $-4.33 * * *$ & 0.90 \\
\hline $\begin{array}{l}\text { The strategies I use to manage cognitive abilities help me function better in } \\
\text { everyday life }^{\dagger}\end{array}$ & $47.0(24.3)$ & 64.0 (19.8) & $-3.00 * *$ & 0.67 \\
\hline
\end{tabular}

Note: $N=23 ;+20 ; d z=$ Cohen’s $d$ effect size; ${ }^{*} p<.05 ;{ }^{* *} p \leq .01 ; * * * p \leq .001$ 
Table 4. Paired samples t-tests comparing self-reported clinical variables at baseline and follow up

\begin{tabular}{|c|c|c|c|c|}
\hline \multirow[t]{2}{*}{ Outcome } & Baseline & Follow-up & \multirow[t]{2}{*}{ t-statistic } & \multirow[t]{2}{*}{ Effect size $\left(d_{z}\right)$} \\
\hline & \multicolumn{2}{|c|}{$M(S D)$} & & \\
\hline Perceived Deficits Questionnaire, total & $44.6(12.1)$ & $41.3(11.0)$ & $2.25 *$ & 0.47 \\
\hline Patient Health Questionnaire-9, total & $16.1(6.4)$ & $14.0(6.9)$ & $2.23 *$ & 0.47 \\
\hline General Self Efficacy, total & $25.4(3.9)$ & $26.4(4.4)$ & -1.65 & 0.34 \\
\hline Rosenberg Self Esteem Scale, total & $20.9(4.9)$ & $21.7(5.2)$ & -1.05 & 0.22 \\
\hline
\end{tabular}

Note: $N=23$; Degrees of freedom=22; $M=$ Mean; $S D=$ Standard Deviation; $d z=$ Cohen's $d$ effect size; * $p<.05$ 


\section{University Library}

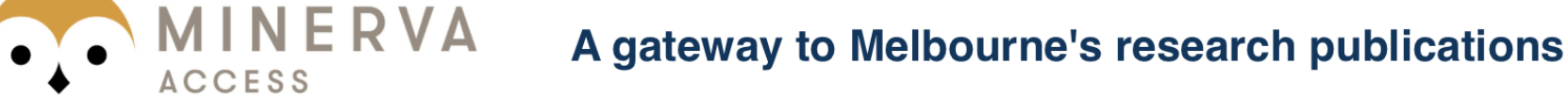

Minerva Access is the Institutional Repository of The University of Melbourne

Author/s:

Bryce, S;Cooke, M;Yuen, HP;Allott, K

Title:

Acceptability, safety and perceived impact of providing a fact sheet to young people about cognitive symptoms in depression

Date:

2020-02-11

Citation:

Bryce, S., Cooke, M., Yuen, H. P. \& Allott, K. (2020). Acceptability, safety and perceived impact of providing a fact sheet to young people about cognitive symptoms in depression. EARLY INTERVENTION IN PSYCHIATRY, 15 (2), pp.328-334. https://doi.org/10.1111/ eip. 12945.

Persistent Link:

http://hdl.handle.net/11343/275391 